www.periodicos.unimontes.br/index.php/caminhosdahistoria

\title{
MARACATU NAÇÃO EM PERNAMBUCO: RAÇA, ETNIA E ESTRATÉGIAS DE ENFRENTAMENTO AO RACISMO
}

\author{
Lady Selma Ferreira Albernaz ${ }^{1}$ \\ Jailma Maria Oliveira ${ }^{2}$
}

Resumo: Este trabalho trata dos sentidos e dos significados coletivos elaborados nos rituais de maracatu, especialmente focando as vestimentas, inicialmente elementos que retratam uma cultura negra e posteriormente, agregando-se referencias à África, remetendo mais claramente a etnização. O trabalho se ancora em trabalho de campo, realizado desde 2009. Analiticamente consideramos as dimensões de gênero e classe para pensar as questões raciais, e autores que tratam especificamente do racismo e seu enfrentamento no Brasil e nas Américas. Os resultados, com dimensões provisórias e sugestão de hipóteses interpretativas, sinalizam para uma continuidade na criação de uma cultura negra, que mesmo não sendo voltadas para o enfretamento ao racismo, é uma ancoragem da organização do movimento negro recente, o qual, por sua vez propicia e a ampliação do conhecimento sobre a África e a inclusão de referencias a este continente por meio das roupas em alguns grupos de maracatu que remetem mais claramente a etnização.

Palavras-chave: Raça, Gênero, Maracatu, Racismo, Movimento Negro.

Abstract: This work treat with the collective senses and meanings elaborated in maracatu rituals, especially focused on the clothes, elements that are portrayed in a black culture, and later adding references to Africa, referring more clearly to ethnicity. The work is anchored in fieldwork, carried out since 2009. Analytically, we consider the dimensions of gender and class to think about racial issues, and authors who specifically deal with racism and its confrontation in Brazil and the Americas. The results, with provisional measures and suggestions for interpretive hypotheses, signal for the creation of a black culture of unknown origin, which are not geared towards confronting racism, it is an organization anchored by the recent black movement, or which, in turn, provides and expands knowledge about Africa and includes references to this continent through clothes in some maracatu groups that refer more clearly to ethnicity.

Keywords: Race, Gender, Maracatu, Racism, Black Movement.

\footnotetext{
${ }^{1}$ Doutora em Ciências Sociais pela Universidade Estadual de Campinas. Professora do Departamento de Antropologia da Universidade Federal de Pernambuco. E-mail: selma.albernaz@gmail.com. ORCID: https://orcid.org/0000-0003-3661-0081.

${ }^{2}$ Doutora em Antropologia pelo Programa de Pós-Graduação em Antropologia - UFPE. Pesquisadora vinculada ao FAGES - Núcleo de Família, Gênero e Sexualidade do Programa de Pós-Graduação em Antropologia PPGA/UFPE, com ênfase nos estudos de Gênero e Cultura Popular. E-mail: jailmamoliveira23@gmail.com. ORCID: https://orcid.org/0000-0003-3213-548X.
} 


\section{Introdução ${ }^{3}$}

Nas observações sobre o maracatu nação de Pernambuco ${ }^{4}$ chamam a atenção os arranjos das relações e classificações de gênero, em interseção com raça e classe, os quais estabelecem posições de homens e mulheres dentro de cada nação. As classificações assim produzidas elaboram valores sobre as expressões e marcas corporais deles e delas e são fundantes para formar sentimentos de um pertencimento racial. Consideramos que os sentidos e os significados coletivos, conformados neste processo, parecem se direcionar para uma etnização simbólica dos elementos usados socialmente para demarcar raça, enquanto inscrita no corpo. É desta questão que tratamos neste artigo ${ }^{5}$.

A investigação de campo vem sendo realizada desde 2009, compondo-se das observações dos seguintes momentos: período dos ensaios nas sedes (iniciados geralmente a partir de setembro e mais intensos de dezembro em diante); período das prévias; período do carnaval $^{6}$ (ALBERNAZ, 2011; OLIVEIRA, 2011). O carnaval é o ponto alto da vida dos grupos de maracatu. Nesta época ocorrem dois eventos importantes: 1- os desfiles das agremiações, promovidos pela Prefeitura do Recife, quando se elegem os campeões $^{7}$; 2- a Noite dos Tambores Silenciosos, em homenagem aos antepassados negros (eguns) ${ }^{8}$. No decorrer do ano os grupos maiores e mais famosos são convidados para participar de festas e/ou oferecer oficinas de percussão e história do maracatu, com ênfase na sua dimensão religiosa. Estes convites podem ser em Recife, outras cidades do país e exterior, notadamente da França e da Alemanha. São estes dados que dão base às interpretações que se seguem.

\footnotetext{
${ }^{3}$ Este trabalho desdobra e aprofunda discussões iniciadas em Jailma Maria Oliveira, Patrícia Georgia Barreto de Lima e Lady Selma Albernaz (2013) quando realizamos uma comparação entre maracatu e bumba meu boi e apresentávamos então a hipótese de etnização da raça no maracatu.

${ }^{4}$ Neste estado existem dois tipos de maracatus, o nação ou baque virado, e o maracatu rural ou baque solto ou orquestra. A distinção baseia-se no ritmo, instrumentos, vestimentas, personagens e localização rural ou urbana.

5 Esta introdução e boa parte do primeiro item deste artigo encontram-se de forma muito semelhante em trabalhos anteriores tais como: Albernaz (2011), Oliveira (2011), Oliveira, Lima e Albernaz (2013). Isto ocorre porque as análises relativas aos objetivos deste artigo, já desenvolvidas naqueles trabalhos, mostram-se ainda pertinentes relativamente à descrição do campo, do maracatu e do referencial teórico.

${ }^{6}$ Em Recife e Olinda as prévias de carnaval iniciam em janeiro e constituem-se de bailes em clubes e de cortejos de rua promovidos pelas agremiações carnavalescas. Os ensaios de maracatus são nas suas sedes ou imediações, sem atrair grande público. No Bairro do Recife (foco das festas carnavalescas da cidade) os ensaios dos maracatus para abertura do carnaval são muito concorridos. Sobre a abertura falaremos adiante.

7 Atualmente o Concurso das Agremiações Carnavalescas do Recife é composto por quatro categorias: Grupo Especial, Grupo 1, Grupo 2 e Grupo de Acesso. Por não ser tema deste artigo não vamos nos deter na explanação dos critérios dessa classificação.

${ }^{8}$ A Noite dos Tambores Silenciosos é realizada deste a década de 1960. A partir de 2002 passou a contar com substancial apoio da Prefeitura do Recife, tornando-se uma das principais atrações do carnaval. Sua fama continuou na década de 2010.
} 
Usamos como autores de referência analítica as obras de Stuart Hall (2003) nas suas discussões de raça e racismo. Para este fim dialogamos ainda com Livio Sansone (2004) no que ser refere às relações possíveis entre raça e etnia. Utilizamos, principalmente, os trabalhos de Marilyn Strathern (2006) na identificação das classificações simbólicas de gênero; e Joan Scott (1996) para pensar as desigualdades de poder. Consideramos a revisão da noção de gênero por Verena Stolcke (2004) e por Rita Segato (1997), que iluminam o debate histórico sobre a interface entre gênero e o enfrentamento das desigualdades que afetam homens e mulheres. Levamos em conta também as discussões sobre interseção de acordo com Stolcke (2006) e Avtar Brah (2006).

O texto está dividido, além dessa introdução, em mais quatro partes. A primeira delas apresenta uma descrição sucinta do maracatu nação. Na segunda parte, focamos os aspectos relacionados à raça e à etnização e como eles podem conotar/denotar valores relativos à definição de raça, na maior parte das vezes em interseção com gênero, a partir da corporeidade. Na terceira parte, focamos as estratégias de enfrentamento ao racismo ou seu obscurecimento, que parecem relevantes pensar como sendo possíveis desdobramentos que se coadunam com a relação entre raça e etnização. Na quarta parte, esboçamos considerações finais, entretanto provisórias, posto que os deslocamentos, entre raça e etnia, sugerem que este tipo de investigação merece ser continuado.

\section{Maracatu nação: personagens e trajetórias}

Os grupos de maracatu nação, de uma forma geral, compõem-se de uma corte, um tipo de corpo de baile, e de um conjunto de batuqueiros, que tocam instrumentos de percussão. Trata-se de um cortejo real com música e dança, que em Pernambuco é considerado uma manifestação exclusiva deste estado ${ }^{9}$. Esse ritual enfatiza, e tem reconhecida, sua relação com as religiões afro-brasileiras. Para alguns maracatuzeiros(as), sua finalidade religiosa é cultuar os antepassados negros (eguns), enquanto que para outras(as) se destina ao culto aos Orixás divindades dos cultos afro-brasileiros ${ }^{10}$.

A corte se estrutura em torno de uma rainha e um rei. Os casais reais são protegidos por um pálio e ladeados por soldados romanos e pajens que levam abanos - todos eles são

\footnotetext{
${ }^{9}$ No Ceará existe maracatu o qual, numa das suas histórias de origem, teria sido criado a partir do modelo Pernambucano. Na Região Metropolitana do Recife pouco se toca neste assunto. Para os cearenses ocorre o inverso (CRUZ, 2008).

${ }^{10}$ Esta filiação religiosa é fonte de muitos debates e requer uma interpretação longa e cuidadosa que comprometem o objetivo deste trabalho. Mas faremos referência, sempre que necessário, às razões religiosas invocadas para justificar a organização dos grupos.
} 
homens jovens ou crianças. Os lanceiros complementam esta guarda real e circulam em volta do cortejo como um todo ao longo das suas apresentações. As rainhas são emblemáticas da corte e principal personagem.

Hierarquicamente a segunda figura mais importante da corte é a Dama do Paço, comumente representada por duas mulheres, cada uma portando uma boneca (calunga) que encarna divindades religiosas, comportando os fundamentos espirituais que protegem o grupo. Acompanhando esta hierarquia há um séquito de casais de nobres, obrigatoriamente um príncipe e uma princesa, e ainda conde, duque, marquês, podendo haver outros títulos que variam em número de um grupo a outro - quanto maior o grupo maior é o número de títulos e de casais. Em alguns casos os casais de nobres adultos são duplicados por casais infantis.

Compõe ainda esta corte um grupo de baianas (ricas e pobres - estas também podem ser chamadas de catirinas), sem um par masculino. Na maioria dos grupos permite-se que estas personagens sejam encarnados por homens. Em alguns maracatus parte das baianas ricas representam figuras dos Orixás, dentre as quais os homens travestidos no geral se destacam pela performance na dança e riqueza das vestimentas (ALBERNAZ, 2016).

Há um caboclo (figura masculina em trajes de pena que se assemelha a um índio) que circula por entre as personagens com uma dança característica - saltos e agachamentos acrobáticos. Sua denominação pelos grupos é caboclo arrea-má. O porta-estandarte leva o estandarte do grupo ricamente bordado e cumprimenta os presentes, abrindo passagem para o cortejo. No desfile carnavalesco todo o cortejo é precedido por uma alegoria, transportada sobre rodas (como um pequeno carro alegórico). Ela apresenta símbolos que sintetizam a identidade do grupo, por exemplo, sereias, leões, peixes, estrelas, caravelas etc. esta alegoria ora está à frente do grupo, ora é o porta estandarte que ocupa a dianteira.

A sequência esquemática desse cortejo costuma ser a seguinte: à frente o porta estandarte o caboclo arreia-má, depois as baianas e, dentre elas, as damas do paço, que protegem todo o séquito. Em seguida as baianas ricas, os casais de nobres, encerrando com o casal real.

Seguindo a corte, durante todo o desfile, vem os(as) batuqueiros(as) (variando entre 15 a 100 pessoas) os quais são liderados(as) por um mestre - que atua como um maestro orientando o conjunto. Os instrumentos são a alfaia, a caixa (ou tarol) e o gonguê, estes se repetem em todos os grupos. São acrescidos a eles, dependendo do maracatu: o abê, o mineiro e o atabaque, isolados ou simultaneamente. Nas apresentações atuais a percussão tem conseguido um grande destaque, que se encarna no mestre. Ele é síntese deste conjunto e 
garante sua harmonia. Destaque-se que, em Pernambuco, no momento da pesquisa de campo existia apenas uma mestra, Joana Cavalcante, do Maracatu Encanto do Pina (Recife).

A partir da década de 1980 o maracatu ganhou grande evidência entre as manifestações de cultura popular em Pernambuco, sendo enfatizado como símbolo regional de identidade. Entretanto, percebe-se que não ocupa a mesma posição do frevo, o ritmo e a dança, que continua sendo um símbolo para afirmar ser pernambucano dentro do Brasil. Isto parece indicar que o maracatu permanece como representante simbólico da cultura negra local, criado e mantido por pessoas pobres oriundas das periferias de Recife e Região Metropolitana.

$\mathrm{Na}$ nossa interpretação este realce atual decorre de dois principais eventos. O primeiro, a reorganização do movimento negro no país, no final dos anos 1970, notadamente o Movimento Negro Unificado (MNU). O MNU retomou a política de enfrentamento ao racismo, associando-se a manifestações de uma cultura popular negra, dentre elas o maracatu nação ${ }^{11}$. Em Pernambuco o movimento negro promoveu diferentes ações para incentivar o reconhecimento e a visibilidade desses grupos de cultura popular na década de 1980 . O segundo evento foi o movimento Mangue Beat, que renovou a música pernambucana, com releituras dos ritmos de cultura popular em associação com pop rock internacional, no estilo world music, com grande impacto local e nacional na década de $1990^{12}$.

A relação entre esta manifestação e afirmação de identidade local possibilitou maior visibilidade, positividade e crescimento dos grupos de maracatu. Coincidentemente ou não, é a partir de então que os laços com a classe média parecem tomar novas configurações. Se anteriormente as aproximações com os grupos tinham finalidades mais de pesquisa e curiosidade folclórica, agora é também de 'integrar-se', passar a atuar nestas manifestações junto com seus criadores, ou compondo grupos inspirados esteticamente no maracatu (ESTEVES, 2008).

Do ponto de vista de gênero e raça, nota-se que essas categorias surgem intimamente associadas à organização social desses grupos e à afirmação de identidade, que parecem ser acionadas para mostrar as divisões dentro da sociedade regional ao tempo em que a distingue da nação. Além disso, também são categorias importantes na sua relação com corpo, uma vez que influenciam nas concepções de corporeidade de homens e de mulheres participantes dos grupos.

\footnotetext{
${ }^{11}$ Hall (2003), especialmente parte 3, analisa a cultura popular negra como um mediador importante para constituição de identidade racial.

${ }^{12}$ Para mais informações sobre os aspectos históricos relacionados ao maracatu nação pernambucano ver Oliveira (2011). Para sua relação com o Mangue beat ver Leonardo Leal Esteves (2008).
} 
Estas operações simbólicas acompanham práticas sociais que dão substancialidade às ações de diferentes agentes, tanto na sua relação com o maracatu como fora dele, nas mediações e interações da vida social. Ao mesmo tempo em que explicam, justificam ou desafiam operações lógicas para compreender e legitimar as desigualdades em termos de raça, gênero e classe. A seguir, trataremos mais especificamente de como raça opera no maracatu nação por meio das expressões e conformações corporais nele expressos, como sentidos de experiência que servem para compreender as ordens sociais em que as pessoas vivem suas relações.

\section{Corpo e suas marcas no maracatu}

A pesquisa de Leonardo Esteves (2008) detém-se na análise de como os indicadores de classe geram tensões relativas ao ingresso de pessoas de classe média nos batuques e, um pouco menos, nas cortes de maracatus históricos do Recife e Região Metropolitana. No seu trabalho o autor relata que pessoas da comunidade, que se prepararam ao longo do ano para tocar no batuque durante as apresentações carnavalescas, são substituídas por pessoas de classe média neste momento tão importante para os grupos de maracatu. As razões para esta substituição se relacionam com a possibilidade de "pagar" ao maracatu por esta participação momentânea ${ }^{13}$. Neste sentido o fator classe parece se sobressair nos arranjos das relações dentro dos grupos, que se expressam na linguagem local como uma oposição entre ricos e pobres, que aparece tensa e desigual.

No histórico sobre o maracatu que referimos antes, ainda que parcial, fizemos notar que os significados do ritual se transformaram ao longo do tempo, passando de valores negativos para um marcador positivo de identidade, tanto da região como das pessoas negras e pobres. A presença da classe média nestes grupos acentua, mais do que dilui, estes sentidos de identidade mediados pelos maracatus. Com a exposição de Esteves (2008) no seu trabalho, pudemos pensar as tensões de classe nestes grupos.

Aqui nos interessa entender as tensões raciais, especialmente como raça e etnia podem se expressar nestas manifestações. Isso nos permite indagar como o maracatu é acionando para significar os sentidos de raça que organizam a sociedade abrangente, no caso em Pernambuco. Se o maracatu foi acionado como símbolo de negritude para enfrentar o racismo

\footnotetext{
${ }^{13} \mathrm{O}$ pagamento nem sempre é reconhecido como tal. Ele se materializa na compra de instrumentos ou da indumentária para o desfile daquele ano.
} 
pelo movimento negro, como raça se faz presente simbolicamente nas suas apresentações públicas e na sua organização?

Para Hall (2003:342) os eventos de cultura popular são importantes para manter símbolos e sentidos de negritude no contexto da diáspora. $\mathrm{O}$ autor analisa como na alta cultura o principal valor é a dimensão logocêntrica, sendo a escrita a sua síntese. Historicamente as pessoas negras estavam fora dessa produção cultural logocêntrica. Em oposição a esta situação, na cultura negra a musica é a "estrutura profunda de sua vida cultural" e o próprio corpo torna-se o seu capital cultural. Tomando esta proposição analítica como referência, cabe voltar o olhar para como a música e a dança aparecem no maracatu expressando uma identidade negra ${ }^{14}$. Em acordo com Strathern (2006), podemos levar em conta também os artefatos, com especial atenção para as vestimentas e seus adereços complementares, como meios para tornar "concretas as idéias das pessoas sobre a natureza das relações sociais"15.

No maracatu a dança se apresenta de maneira muito semelhante àquela que é executada dentro dos terreiros nos momentos festivos de celebração aos Orixás. Por meio de passos ritmados, de movimentos alternados de braços e do meneio do corpo que gira entre um compasso e outro, ela se constitui como um elemento que embala toda corte ao som do baque das alfaias. Pela sua semelhança com a dança dos Orixás, em alguns grupos, a exemplo do Leão Coroado e do Maracatu Estrela Brilhante de Igarassu, as mulheres dançam de forma compenetrada, como que demonstrando se tratar não só de um momento festivo, ligado ao carnaval, mas também de reverência ao sagrado. Nota-se aqui a presença do corpo como capital cultural, na medida em que a corporeidade que ele encena está associada ao ser negro, tanto para o senso comum, como para o pensamento hegemônico ratificado nas obras dos intelectuais. A produção de folcloristas e de estudiosos(as) do carnaval tende a caracterizar as maneiras deste corpo negativamente, ora a força do trabalho que não se faz acompanhar da razão, ora o corpo da dança ritmada e repetitiva relacionada com o transe (Oliveira, 2011).

No que se refere às indumentárias das mulheres a relação parece não fugir a regra, o que significa dizer que também existe semelhança com as vestimentas utilizadas por elas nos

\footnotetext{
${ }^{14}$ Em trabalho anterior fizemos uma análise da música no maracatu, focando a junção dos batuques de diferentes grupos na Abertura do Carnaval do Recife (Albernaz, Oliveira, 2015). Em trabalho de 2016 o foco maior foi a dança, a partir de gênero (Albernaz, 2016).

${ }^{15}$ Aqui estamos estendendo para a compreensão de raça a definição desta autora sobre como gênero se expressa nas relações sociais por meio de artefatos, como se vê nesta citação: Entendo por 'gênero' aquelas categorizações de pessoas, artefatos, eventos, seqüência etc. que se fundamentam em imagens sexuais - nas maneiras pelas quais a nitidez das características masculinas e femininas torna concretas as idéias das pessoas sobre a natureza das relações sociais. (Strathern, 2006:20). Grafia conforme o original.
} 
terreiros ${ }^{16}$. Na corte do maracatu em geral as roupas femininas são longas e de variadas cores, feitas de cetim, paetê, brocado, lamê e renda, sendo ricamente trabalhadas, com bastante babados e bordados. O valor dos tecidos acompanha os recursos que o grupo dispõe, mas todos tentam aparentar luxo na sua confecção, proporcionando uma grandiosidade ao figurino. Outras personagens, como as catirinas, vestem roupas de chitão, mais simples na sua feitura por não possuírem bordados ou brilhos. Isto porque elas representam as roupas das mulheres escravas, segundo as percepções atuais.

Aqui cabe observar as roupas das mulheres do terreiro e as roupas da corte do maracatu repetem os estilos e formas daquelas usadas pelas cortes europeias no séc. XIX, trazidas no período colonial para o Brasil. Obviamente que elas são atualizadas em novas formas e estéticas e, além disso, muito importante para discussão que fazemos aqui, são transformadas em símbolo de uma cultura negra. Interpretamos assim porque são roupas que não se usam no cotidiano e, sobretudo, são roupas associadas com os terreiros o que pode levar a segunda associação acima referida - como sendo símbolo de uma cultura negra ${ }^{17}$.

No que se refere aos homens da corte do maracatu, eles se vestem ao estilo Luís XV, mantendo o mesmo padrão de tecidos luxuosos das mulheres. Esse tipo de figurino deles em nada se assemelha aos trajes masculinos usados nos terreiros. Entretanto, as roupas masculinas do batuque podem ser vistas como tendo algum tipo de relação com as roupas das religiões de matriz africana. Aprofundaremos essa discussão logo a seguir, mas salientamos antes que, fugindo do modelo mais canônico da estrutura da corte, alguns maracatus trazem um grupo de dançarinos(as), com roupas africanizadas e que executam uma dança comum aos balés afro. Ou seja, com uma coreografia assemelhada a danças tribais africanas, ou remetendo a uma África mítica como terra de origem da população negra brasileira ${ }^{18}$. Esta presença, ainda que pouco frequente, parece se relacionar com mudanças que observamos no estilo de roupa usada pelos(as) batuqueiros(as).

Olhando numa perspectiva de comparação temporal os batuques dos maracatus retratados em fotografias antigas, apresentavam vestimentas feitas com tecidos lisos - ou listrados - de cores mais claras e pareciam de algodão ou outro fio rústico. As imagens de

\footnotetext{
${ }^{16}$ As roupas dos terreiros das religiões de matriz africanas não são uniformes. A comparação acima se faz especificamente com aqueles que usam o padrão da corte europeia que se popularizou no Brasil como sendo a roupa característica das "baianas".

${ }^{17}$ Desconhecemos bibliografia que tratem das razões da permanência deste estilo de roupa nos terreiros e em diferentes rituais e festas carnavalescas (como as baianas das escolas de samba).

18 Entretanto, como este tipo de personagem não foi enfatizado pelos(as) nossos(as) entrevistados(as) não aprofundamos a discussão aqui. Consideramos que esta questão merece ser explorada em estudos posteriores, para melhor desdobrar nossa hipótese da etnização.
} 
Katarina Real, particularmente duas delas ${ }^{19}$, são bons exemplos do que estamos falando, bem como a que seque abaixo:

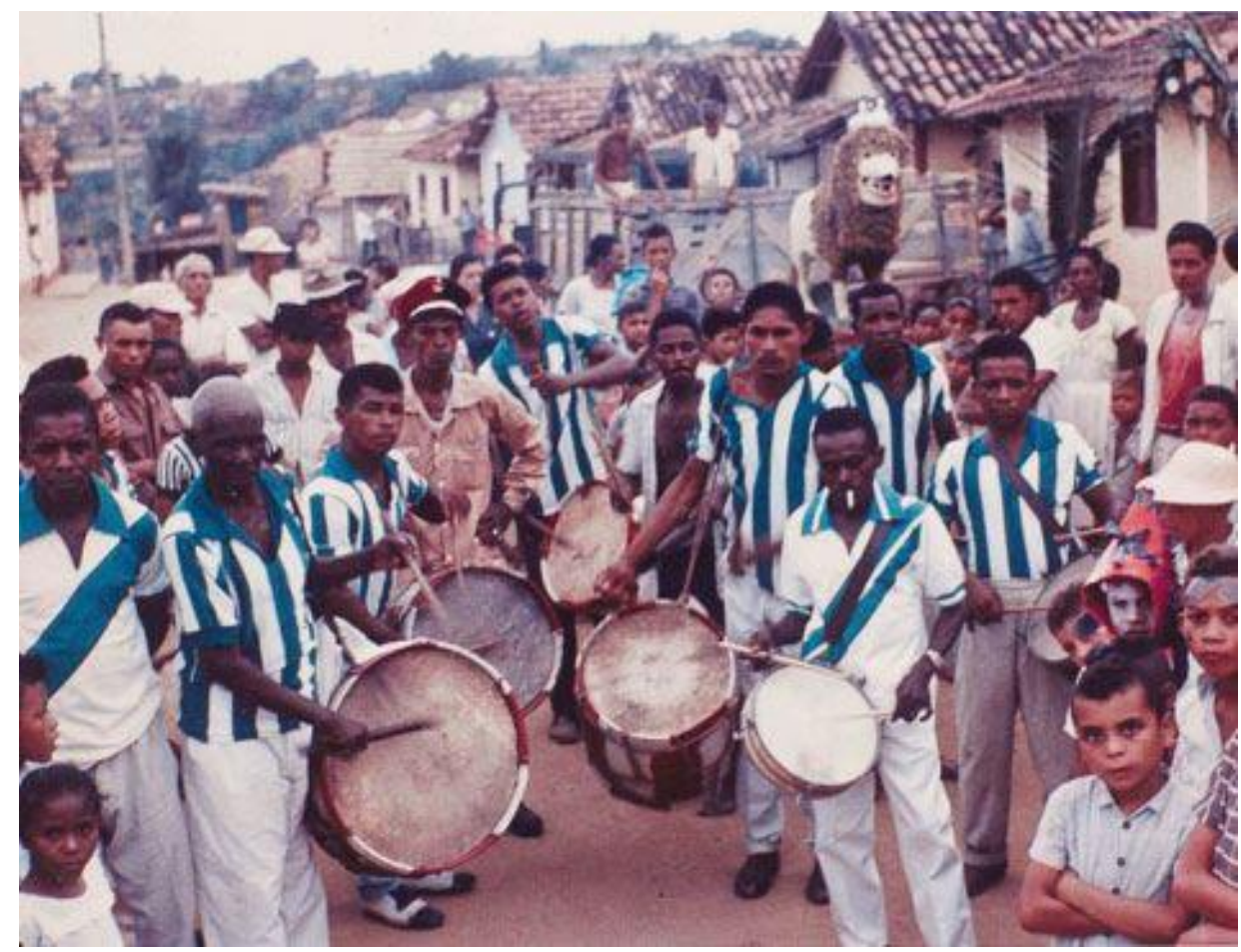

Batuque Maracatu Leão Coroado. Foto Katarina Real.

Fonte: https://www.folhape.com.br/obj/147/266376,475,80,0,0,475,365,0,0,0,0.jpg

Ao iniciar nossas observações percebemos que no batuque os homens se vestem com calça e camisa de manga curta e na cabeça costumam usar chapéu de palha, boné, torço ou bandana, tudo com uma mesma padronagem de cor e estampas. Tais roupas são simples, quando comparadas com a corte. Também se assemelham aos trajes masculinos usados em alguns terreiros. Por sua vez, sua forma e os tecidos de algodão mais rústicos, tanto remetem à população pobre, como parecem se ligar a uma herança da escravidão. Neste sentido, consideramos que tais vestimentas sugerem uma afirmação de uma cultura negra, especialmente pela semelhança com as roupas dos terreiros.

$\mathrm{Na}$ continuidade do trabalho de campo passamos a notar que as roupas das pessoas do batuque incorporavam arremates de tecidos com estampas de inspiração africana. Notamos que na Nação Porto Rico a inovação é mais acentuada, chegando a usar calças e saias feitas

\footnotetext{
19 Ver: http://digitalizacao.fundaj.gov.br/fundaj2/modules/busca/listar_projeto.php?cod=29\&from=215\# consultado em 27/05/2019, especialmente as seguintes imagens: http://digitalizacao.fundaj.gov.br/fundaj2/modules/visualizador/i/ult_frame.php?cod=2006 http://digitalizacao.fundaj.gov.br/fundaj2/modules/visualizador/i/ult_frame.php?cod=2007 27/05/2019.
}

Caminhos da História, v.24, n.1 (jan./jun.2019) 
inteiramente com tecidos desse tipo. Pode-se pensar que se assemelham com blocos africanizados especialmente no estilo do carnaval baiano.

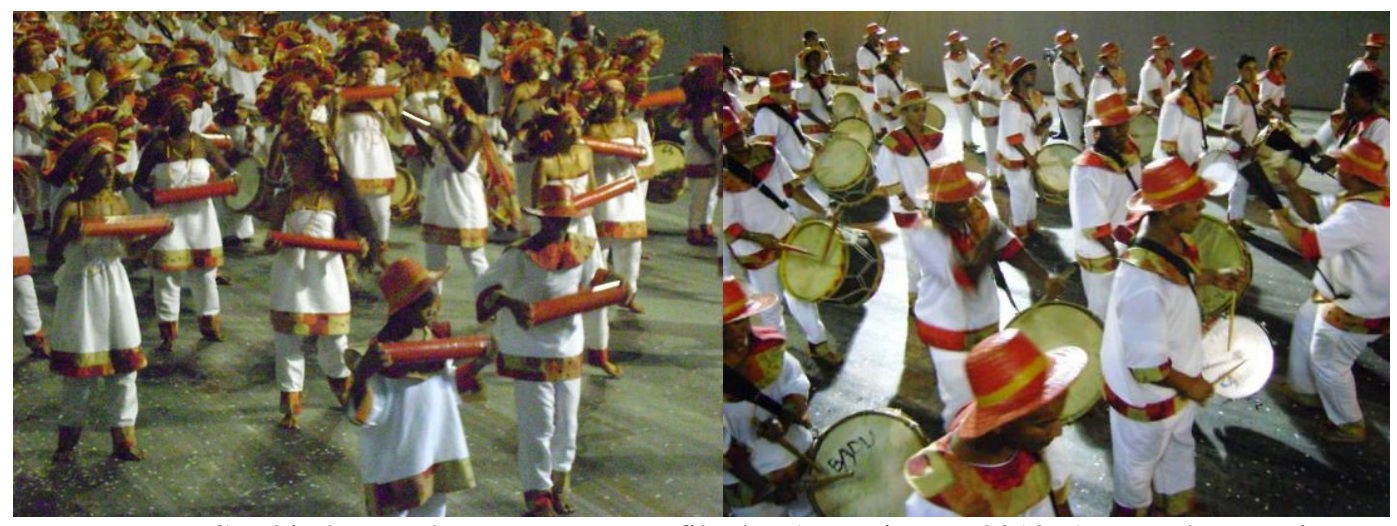

Maracatu Cambinda Estrela - Batuque. Desfile das Agremiações 2010. Acervo da pesquisa

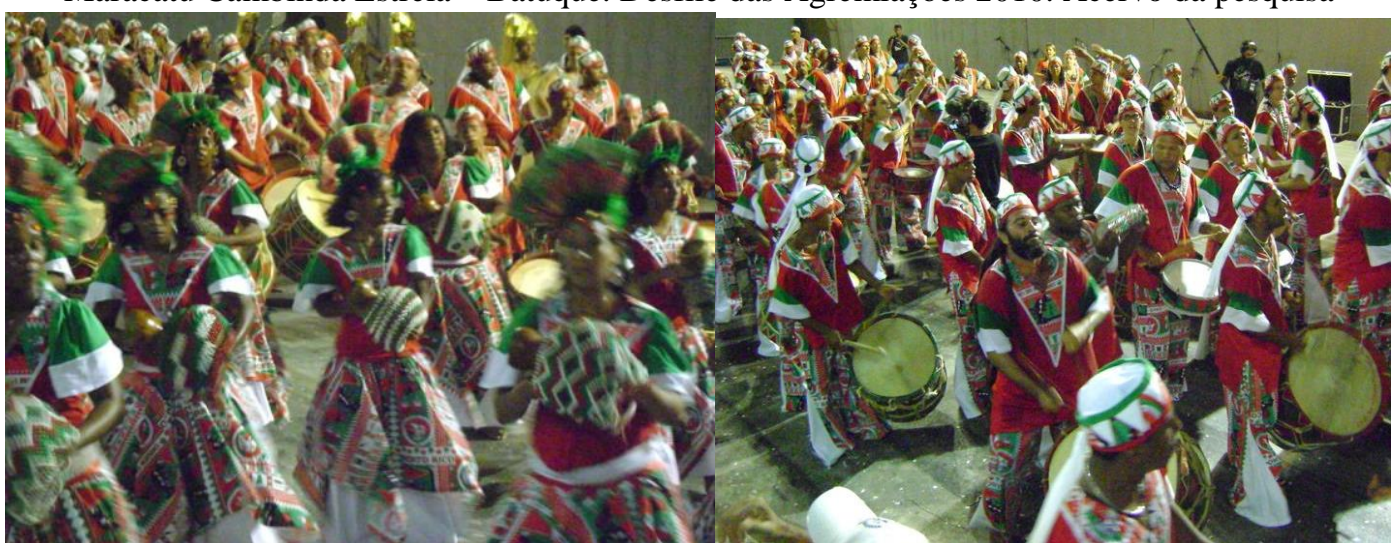

Maracatu Porto Rico - Batuque. Desfile das Agremiações 2010. Acervo da pesquisa

A composição mista do batuque, na atualidade, nos fez perceber que marcadores de gênero também se tornam importantes nas vestimentas ${ }^{20}$. No que se refere à forma as roupas dos homens, como descrita acima, exprimem sua masculinidade, que aparece cruzada com um tipo de africanidade e também com o sagrado, até certo ponto, pela sua semelhança com as roupas do terreiro.

No batuque as mulheres vestem blusa e saia (longa ou curta) ou blusa e calça (ate metade da panturrilha), sendo a blusa quase sempre decotada. Aqui parece haver um deslocamento da associação entre as indumentárias do maracatu e a que se adota no terreiro para as mulheres, de uma forma geral, sendo a fotografia do batuque do Porto Rico um exemplo pouco frequente. Este distanciamento na forma das roupas parece obscurecer que elas são mulheres, por isso ele é compensado por adereços na cabeça ou penteados, complementados por brincos e bijuterias chamativas (ALBERNAZ, 2011). Os artefatos querem acentuar distinções de gênero, sugerindo também sensualidade por meio da beleza.

\footnotetext{
${ }^{20}$ Vale ressaltar que a participação das mulheres nas apresentações públicas do batuque, até onde pudemos verificar, iniciou-se na segunda metade da década de 1980 (ALBERNAZ, 2011 e OLIVEIRA, 2011).
} 
Entretanto, o que parece mais sugestivo é que tanto as mulheres do abê, quanto os homens (batuqueiros) chamam para uma afirmação racial e ao mesmo tempo para uma etnização por conta dos padrões africanos das suas vestimentas - que são mais visíveis nestas duas categorias de pessoas dentro do batuque. As roupas das meninas e das mulheres que tocam abê parecem guardar esta relação de africanização com maior força, comparando-se a roupas daquelas que tocam alfaia. Esse tipo de vestimenta, mesmo que possa invocar uma indumentária de inspiração africana não lembra necessariamente os Orixás. Ou seja, a etnia não é mais ligada ao que ocorre apenas no terreiro, mas também por uma invocação a própria África, sem a mediação do sincretismo que caracteriza boa parte da história das religiões de matriz africana ${ }^{21}$.

Fazendo um paralelo entre as indumentárias femininas e masculinas dentro do batuque é curioso notar, que embora existam traços de africanidade em ambas, é na vestimenta dos homens que essa marca africana parece se mostrar de forma mais evidente. Sendo o batuque um espaço de predominância de homens e simbolicamente masculino, pode-se pensar que sua maior ênfase na africanidade se relaciona com gênero. Uma maneira de acentuar sua masculinidade frente às mulheres que tocam alfaia. Mas pode sugerir que os homens se percebem como portadores mais legítimos do que elas desta mesma africanidade. Esta interpretação tem um caráter provisório, e requer maiores aprofundamentos. Não pudemos deixar de notá-la, entretanto, posto que a interseção entre etnicidade e gênero tem sido pouco ou nada debatido neste campo empírico ${ }^{22}$.

Estas diferentes formas de colocar o corpo em cena configuram uma maneira própria de significá-lo, seja por meio dos instrumentos ou através das vestimentas. Mas para além do conteúdo simbólico destes artefatos a performance por meio dos movimento da dança concretizam esta corporeidade. Conforme David Le Breton (2009), enquanto construção simbólica, “...o corpo sempre está compreendido na trama social de sentidos.” (LE BRETON, 2009, p. 32). E conforme Hall (2003), citado antes, na cultura negra a música se sobrepõe ao logocentrismo da alta cultura ocidental, e acrescentaríamos, ela quase sempre se faz acompanhar pela dança.

No maracatu a dança e a música mantêm uma estreita relação com o universo das religiões de matriz africana, afirmando um tipo de negritude no cenário da cultura

\footnotetext{
${ }^{21} \mathrm{O}$ debate sobre usos de símbolos e objetos africanos, bem como sobre se a África imaginada corresponde ou não ao continente africano e sua variedade cultural resultou polêmicas em seminários e encontros acadêmicos e em publicações. Aqui não vamos nos estender nesta discussão. Ver Sansone (2004. Especialmente capítulo 2).

${ }^{22}$ Os trabalhos de Verena Stolcke (2006) e Avtar Brah (2006) sinalizam como sendo fundamental, para compreender as desigualdades de gênero e de etnia, levar em conta como estes marcadores se intersecionam na composição das relações sociais, demarcando as posições adequadas para cada sexo.
} 
pernambucana. Mais recentemente, se nossas interpretações estiverem corretas, os grupos de maracatu parecem se encaminhar para fortalecer este sentido étnico ao se relacionar diretamente com símbolos creditados como tendo origem na África. Pode-se pensar a dança, como um modo de materializar no corpo, uma afirmação de pertencimento racial, que parece se somar a possíveis sentidos étnicos neste tipo de identidade.

A maneira de dançar e o tipo de roupa que se veste caracterizam-se como uma leitura do que deve ser uma África, ou como ela pode ser imaginada. Por meio dessa leitura a beleza e o charme são também enfatizados, sendo reforçados pelas performances do corpo na execução da música e da dança. Ao que nos parece, o corpo torna-se muito mais étnico do que racializado, porque os artefatos e as performances propiciam uma encenação que se desloca da forma corporal. Ou seja, este corpo pode se distanciar dos traços diacríticos da cor, tipo de cabelo, nariz ou boca - traços acentuados no Brasil para estabelecer as classificações do que seja uma pessoa negra ou branca. Por isso a ideia de uma africanidade, mais étnica do que propriamente racial, parece mais presente nesta forma de dar significado ao corpo de homens e mulheres dentro do maracatu.

\section{Etnia, raça e enfretamento ao racismo no maracatu}

Neste item destacamos um evento para discorrer um pouco mais, pensando agora em nível político, sobre a junção entre raça e etnia no maracatu nas últimas décadas. O evento que escolhemos é a Abertura do Carnaval recifense, o qual se tornou, durante 16 anos, um ponto alto do carnaval recifense para os grupos de maracatu, juntamente com o Desfile das Agremiações e a Noite dos Tambores Silenciosos. Vejamos como o descrevemos anteriormente:

A primeira atração da Abertura do Carnaval [do Recife] são as nações de maracatu, regidas por Naná Vasconcelos - percussionista pernambucano de fama internacional. Eleito por oito vezes pela revista americana Down Beat o melhor percussionista do mundo, e ainda hoje é considerado uma autoridade mundial em percussão, Naná é reconhecido como o idealizador desta orquestra de tambores, que teve início em 2002. Desde sua criação, um dos objetivos explícitos da cerimônia é contribuir para superar as disputas históricas entre os grupos de maracatu. Com isso procurou-se celebrar a união do povo negro, conferir visibilidade aos ritmos africanos e dessa forma constituir-se numa ação de enfrentamento ao racismo, por meio da valorização da cultura negra. Sua importância também é demonstrada pela participação anual de cantores(as) de fama nacional e internacional nas apresentações, junto com a orquestra de tambores.

Esta apresentação de maracatus tem uma característica peculiar, pois ao invés dos grupos tocarem separadamente, como sempre fazem, eles são reunidos para execução conjunta de uma sequência de canções, cantadas por 
um coral e/ou por artistas convidados/as, ao som de uma 'sinfonia de tambores'. Cada nação pode levar até 50 percussionistas, somando, em média, 500 batuqueiros(as) ${ }^{23}$. (Albernaz, Oliveira, 2015, p. 76-7) ${ }^{24}$

Havia outras peculiaridades na Abertura. Os tambores ficavam ao rés do chão. Naná e os(as) cantores(as) estavam posicionados num palco, com dois níveis. Cabe destacar aqui as vestimentas usadas por Naná, posicionado como regente da festa no primeiro nível do palco. Ele vestia uma longa bata de estilo africano, que somada às suas características físicas, alto e forte, parecia remeter não apenas a um grande músico, mas a uma liderança política com elevada posição hierárquica. Remetia também à idéia de uma liderança espiritual, posto que no mesmo nível em que ele se localizava no palco, ficavam as mães de santo, com as roupas suntuosas usadas nos terreiros, complementadas pelos majestosos torços de cabeça. Os buquês de flores que elas portavam sinalizavam para o afeto, devotamento e respeito recebido por parte das pessoas seguidoras da religião ou parte da comunidade dos seus terreiros. Mais acima, na boca de cena do segundo nível do palco, o coral "Vozes Nagô" cantava loas de inspiração na cultura africana, estando as mulheres que o formava vestidas com roupas claras e igualmente adornadas com torços caprichosamente compostos nas suas amarrações.

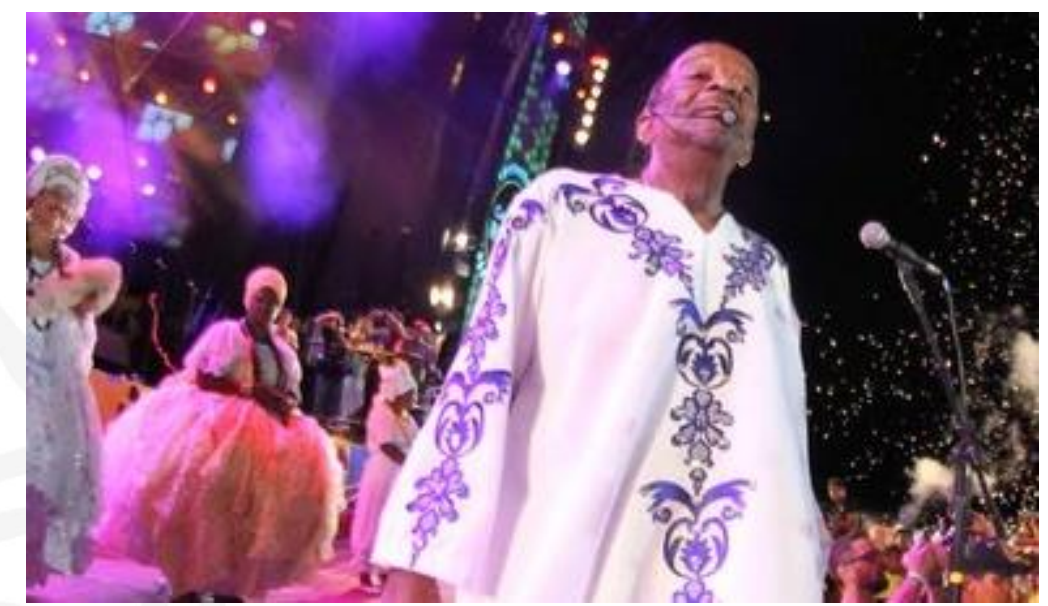

Do palco, Naná Vasconcelos comandou onze nações de marcatu 05/02/2016 (Foto: Aldo Carneiro/ Pernambuco Press) ${ }^{25}$

\footnotetext{
${ }^{23}$ A orquestra de tambores é composta por: nove nações do Grupo Especial; a nação mais bem pontuada no concurso do carnaval do ano anterior do Grupo 1, e mais uma nação convidada. Esta composição segue a classificação dos grupos para o Concurso de Agremiações Carnavalescas da Prefeitura do Recife, constituído por quatro categorias: Grupo Especial, Grupo 1, Grupo 2 e Grupo de Acesso.

${ }^{24}$ Naná Vasconcelos faleceu em março de 2016, um pouco depois de fazer a ultima abertura do carnaval em Recife com a Orquestra de Tambores dos maracatus.

${ }^{25}$ Disponível em http://g1.globo.com/pernambuco/carnaval/2016/noticia/2016/02/nana-vasconcelos-da-largadapara-o-carnaval-do-recife-no-marco-zero.html, consultado em 31 de maio de 2019.
} 
No resplendor da festa a africanidade, dos maracatus e das religiões de terreiro, era ressaltada pelo mestre de cerimônia, que pontuava as apresentações das nações, celebrando a resistência negra à escravidão. As lideranças de maracatu e das comunidades de terreiro somavam-se às figuras históricas que enfrentaram a escravidão lutando pela abolição. Nitidamente a cerimônia de abertura do carnaval era uma afirmação de uma identidade negra. O mestre de cerimônia proferia frases de denúncia do racismo, de clamor contra a desigualdade, de defesa da justiça social. As nações de maracatu eram elogiadas por sua maestria musical, mas, sobretudo ele descrevia os grupos como um espaço social de resistência política do povo negro contra as perseguições e as desigualdades resultantes do racismo. Era um chamado para dar continuidade à resistência do povo negro e para alcançar uma liberdade efetiva e o direito de professar sua cultura, bem como para conquistar o respeito e dignidade para sua cor. Vale notar, que parte das pessoas que entrevistamos, ainda na primeira década do século XXI, já declarava a perseguição das novas igrejas evangélicas aos maracatus e às religiões de matriz africana, com argumentos de demonização da cultura e de negação da humanidade para as pessoas negras. Tal perseguição, infelizmente, só vem aumentando nos últimos anos com o crescimento das igrejas neopentecostais nas suas diferentes denominações.

O público, nas vezes que acompanhamos a abertura com os tambores, tinha uma composição variável em termos de idade, sexo e cor, bem como variava seu tamanho, às vezes muito denso, às vezes rarefeito em quantidade. Mas eram inegáveis as expressões atentas, o acompanhamento do canto no momento do refrão, a emoção nas feições - misto de alegria, melancolia e vitória. Ou seja, havia da parte do publico uma identificação de raça, acompanhada de um sentido de celebrar a cultura africana e, não menos importante, um sentido de luta pela liberdade. Assim, o público irmanava-se a Naná e aos maracatus na idéia de afirmar a africanidade, a negritude e, acima de tudo, a luta de enfrentamento ao racismo que ainda perdura, para nosso pesar.

A partir daqui nos deslocaremos das descrições do maracatu, para tratar da etnização e do diálogo com o trabalho de Sansone (2004). Aqui também encerramos a escrita deste artigo, que terá dois eixos: 1 - como a comunidade do maracatu expressa sua resistência ao racismo unindo-se ao movimento negro por meio de elementos culturais; 2 - como o debate intelectual vem analisando o movimento negro na sua relação com o racismo, cultural e socialmente 
estruturante da sociedade brasileira. Obviamente não esgotaremos a discussão, ela se afigura mais a uma conclusão propositiva do que de encerramento do debate.

Consideramos que a forma de vestir-se para encenar o maracatu, mesmo antes do uso das roupas com padronagem africana, já era uma forma de falar da cultura africana, de afirmar este pertencimento, se não à África, mas a uma comunidade de pessoas de cor, pobres e periféricas. Não usamos o termo negro porque poderia ser abusivo para o passado, na medida em que sua utilização pelo movimento não corresponde a uma categoria nativa, mas sim como uma categoria política e sociológica com finalidades de enfrentar o racismo (Guimarães, 2008).

Concordando com Sidney Mintz e Richard Price $(2003)^{26}$ seria oportuno relembrar que as conformações culturais da população africana nas Américas, formaram-se tendo por base as instituições ocidentais e o regime desigual da escravidão. Para estes autores as culturas negras aqui desenvolvidas tinham uma dimensão nova, em relação às culturas africanas de origem. Por isso, levantamos a hipótese de que as vestimentas usadas nos grandes rituais festivos, dentre eles o maracatu, tem relação com esta cultura africana, ainda que remetam, em sua estética, às formas ocidentais. Reforça esta hipótese o fato desta roupa vestir um corpo cuja gestualidade, ligada com a musicalidade, remete a uma cultura ancestral africana repassada oralmente e corporalmente. Nesse sentido, as roupas das baianas não são apenas roupas semelhantes as das sinhazinhas, são roupas que mediam expressões de uma cultura negra criada e transmitida nos terreiros e nos cultos aos orixás, encadeadas por cantos e músicas percussivas cujos instrumentos remetem à África.

Ao se pensar assim, a idéia do enfrentamento ao racismo como não relacionado com dimensões étnicas perde força, pois as diferentes modalidades de resistência para manter uma cultura negra nas Américas se fez tendo por base instituições ocidentais, e em estados e sociedades dominadas por pessoas brancas. Dessa forma, mesclavam-se dimensões culturais negras e brancas, mas a finalidade era levar adiante culturas de base africana modificadas e dominadas por um sistema de escravidão. Dito isso, a maneira como no maracatu, mesmo antes da aproximação do movimento negro deste tipo de prática, é ela mesma uma forma de evidenciar diferenças culturais frente aos brancos, e nesse sentido, sua dimensão estética relaciona-se com dimensões étnicas por meio da continuidade desta cultura ao longo do tempo. Manutenção feita por meio da oralidade, da musica, dos instrumentos, da dança e também das vestimentas.

\footnotetext{
${ }^{26} \mathrm{O}$ que se segue inspira-se nas conclusões e propostas analíticas de Mintz e Price, bem como das reflexões de Hall (2003)
} 
Pensamos que a aproximação do movimento negro dos maracatus, bem como do alargamento do conhecimento histórico e antropológico sobre maracatus, terreiros e outros rituais afro-brasileiros, que demonstraram suas relações com a resistência à escravidão, proporcionou a expansão dos contatos com a África e sua cultura atual. Sendo assim a incorporação de elementos africanos nessas manifestações, que antes não estavam presentes, tornou-se mais plausível sem significar uma ruptura com a tradição e com a ancestralidade que os maracatus comportam e atualizam.

Nesse sentido, as hipóteses interpretativas de Sansone, que sugere uma ênfase na negritude sem haver etnicidade nos parece frágil. Tanto na sua forma canônica, como na sua forma que incorpora elementos africanos o maracatu afirma uma cultura negra, e se assim o é, remete a uma identidade étnica. A ênfase na dimensão racial da luta do movimento negro não poderia ser diferente, posto que os grupos que celebram rituais de cultura negra o fazem para afirmar sua negritude, sem necessariamente ter ferramentas para enfrentar o racismo no cotidiano. Essa fragilidade precisa ser enfrentada nos nossos estudos, para melhor entender como eles são resistência da cultura negra, sem necessariamente ter forças para afirmar o ser negro racialmente. Por sua vez, não é por acaso que o movimento negro dos anos 1970 busquem nestes grupos a inspiração para tratar da negritude aliado com uma cultura negra ancestral esquecida e perseguida.

\section{Referências Bibliográficas}

ALBERNAZ, L. S. F.. "Homens que dançam: gênero, corpo, raça e travestilidade no maracatu". In: VIEIRA, L. L.; RIOS, L. F.; QUEIROZ, T. N. (Orgs.). Gays, lésbicas e travesti em foco: diálogos sobre sociabilidade e acesso à educação e saúde. 1ed.Recife: EdUFPE, 2016, v. 1, p. 48-82.

ALBERNAZ, L. S. F.; OLIVEIRA, J. "Sinfonia de tambores: comunicação e estilos musicais no maracatu nação de Pernambuco". Revista Anthropológicas, v. 26, p. 75-102, 2015.

ALBERNAZ, Lady Selma F. "Gender and musical performance in Maracatus (PE) and Bumba Bois (MA)". Vibrant (Florianópolis), v. 8, n 1, p. 324-353, janeiro/junho. 2011. Disponível em: http://www.vibrant.org.br/issues/v8n1/lady-selma-ferreira-albernaz-genderand-musical-performance-in-maracatus-pe/

BAKHTIN, Mikhail. M. A cultura popular na Idade Média e Renascimento: o contexto de François Rabelais. São Paulo/Brasília: HUCITEC/UNB, 1987.

BRAH, Avtar. "Diferença, diversidade, diferenciação". Cadernos Pagu [online]. 2006, n.26, pp. 329-376.

CAVALCANTI, Maria Laura Viveiros de Castro. "Cultura popular e sensibilidade romântica: as danças dramáticas de Mário de Andrade". In: Revista Brasileira de Ciências Sociais. Fev, vol.19, no. 54. p. 57-78, 2004.

CORRÊA, Mariza. "Sobre a invenção da mulata". Cadernos Pagu, Campinas, n.6-7, p. 35$50,1996$. 
CRUZ, Danielle Maia. Sentidos e significados da negritude no maracatu Nação Iracema. Dissertação de Mestrado em Ciências Sociais, UFC, Fortaleza, 2008.

ESTEVES, Leonardo Leal. "Viradas" e "marcações": a participação de pessoas de classe média nos grupos de maracatu de baque-virado do Recife-PE. 2008. Dissertação de Mestrado em Antropologia, UFPE, Recife.

FRANTZ, Fanon. Pele negra, máscaras brancas. Salvador: EDUFBA, 2008.

GOMES, Nilma Lino. Sem perder a raiz: corpo e cabelo como símbolos da identidade negra. Belo Horizonte: Autêntica, 2006. (Cultura negra e identidades).

GUIMARÃES, A. S. A. "Raça, Cor e Outros Conceitos Analíticos". In: Osmundo Pinho; Livio Sansone. (Org.). Raça: novas perspectivas antropológicas. 1ed.Salvador: EDUFBA, 2008, v. 1, p. 63-82.

HALL, Stuart. Da diáspora: identidades e mediações culturais. Belo Horizonte: Editora UFMG; Brasília: Representações da UNESCO no Brasil, 2003.

LE BRETON, Divid. Adeus ao corpo: Antropologia e sociedade. $4^{\text {a }}$ Ed. Campinas - São Paulo: Papirus, 2009.

MINTZ, Sidney e PRICE, Richard. O nascimento da cultura Afro-Americana. Uma perspectiva antropológica. $2^{a}$ Edição revista. Rio de Janeiro: Pallas -Universidade Cândido Mendes, 2003.

OLIVEIRA, J.; LIMA, P. G. B. ; ALBERNAZ, L. S. F. . "Encenando bumba boi e maracatu: gênero, raça e corpo entre brincantes". In: Russell Parry Scott; Dayse Amâncio dos Santos. (Org.). Novos estudos sobre família e gênero: cotidianos, direitos e performances. $1^{\mathrm{a}}$ ed. Recife: Ed. Universitária da UFPE, 2013, v. 18, p. 119-144.

OLIVEIRA, Jailma Maria Rainhas, mestres e tambores: Gênero, corpo e artefatos no maracatu nação pernambucano. Dissertação de Mestrado em Antropologia, UFPE, Recife, 2011.

SANSONE, Lívio. Negritude sem etnicidade: o local e o global nas relações raciais e na produção cultural negra do Brasil, trad. de Vera Ribeiro, Salvador/Rio de Janeiro, Edufba/Pallas, 2004, 335 pp.

SCOTT, Joan. Gênero: uma categoria útil para a análise histórica. Recife: SOS Corpo Gênero e Cidadania, 1996.

SEGATTO, Rita Laura. "Os percursos de gênero na antropologia e para além dela". Revista Sociedade e Estado. Brasília, v XII, nº 2, p. 235-261, 1997.

STOLCKE, Verena. "La mujer es puro cuento: la cultura del género". Estudos Feministas. vol. 12, 77-102, 2004.

STOLCKE, Verena. 'O enigma das interseções: classe, 'raça', sexo, sexualidade: a formação dos impérios transatlânticos do século XVI ao XIX”. Revista Estudos Feministas. Abr 2006, vol.14, no.1, p.15-42.

STRATHERN, Marilyn. $O$ gênero da dádiva: problemas com as mulheres e problemas com a sociedade na Melanésia. Campinas, Editora da UNICAMP, 2006. 